Original article

\title{
Beden Eğitimi ve Spor Öğretmen Adaylarının Eğitsel Oyun Oynatma Öz Yeterliliğinin Demografik Değişkenler Açısından İncelenmesi
}

\author{
Examination of Educational Game-Playing Self-Efficacy of Physical \\ Education and Sports Teacher Candidates in Terms of Demographic \\ Variables
}

\section{Tugay Çintesun}

Department of Physical Education and Sports Teaching, Institute Social Sciences, Ardahan University, Ardahan, Turkey

\begin{abstract}
Özet
Bu araştırmanın amacı beden eğitimi ve spor öğretmen adaylarının eğitsel oyun oynatma öz yeterliliklerinin sosyo-demografik değişkenler açısından değişimini incelemektir. Bu çalışma genel tarama modelinde tasarlanmıştır. Çalışmanın örneklemini Kafkas Üniversitesi Beden Eğitimi ve Spor yüksekokulu beden eğitimi ve spor öğretmenliği bölümünde farklı sınıf kademelerinde öğrenim gören 111 öğretmen adayı oluşturmaktadır. Araştırmada veri toplama aracı olarak 11 madde ve 3 faktörlü Eğitsel Oyun Oynatma Öz Yeterlilik Ölçeği kullanılmıştır. Verilerin analizinde Aritmetik ortalama, standart sapma ve MANOVA testleri kullanılmıştır. Araştırma sonucu elde edilen bulgular incelendiğinde, beden eğitimi ve spor öğretmen adaylarının eğitsel oyun oynatma konusunda öz yeterliliklerinin yüksek olduğu ancak uygulama konusunda öz yeterliliklerinin ölçeğin diğer boyutlarına göre daha düşük olduğu sonucu elde edilmiştir. Araştırmanın diğer bir alt probleminde öğretmen adaylarının eğitsel oyun oynatma ile cinsiyetleri arasında istatistiki açıdan anlamlı bir fark bulunmadığı ancak kadın öğretmenlerin öz yeterlilik puan ortalamalarının erkek öğretmen adaylarına oranla daha yüksek olduğu sonucu elde edilmiştir. Son olarak öğretmen adaylarının eğitsel oyun oynatmaya yönelik öz yeterlilikleri ile sınıf değişkeni arasındaki ilişki incelendiğinde ise oyun oynatma öz yeterlilikleri ile sınıf değişkeni arasında istatistikî açıdan anlamlı bir fark bulunmadığı sonucu elde edilmiştir.
\end{abstract}

Anahtar Kelimeler: Eğitsel oyun, öz yeterlilik, beden eğitimi ve spor.

\begin{abstract}
The aim of this study is to examine the change in educational game self-efficacy of physical education and sports teacher candidates in terms of socio-demographic variables. This study is designed in general scanning model. The sample of the study consists of 111 teacher candidates studying at different grade levels in the department of physical education and sports teaching at Kafkas University School of Physical Education and Sports. In the study, 11 items and 3-factor Educational Game-Playing SelfEfficacy Scale were used as data collection tools. Arithmetic mean, standard deviation and MANOVA tests were used to analyze the data. When the findings obtained as a result of the research were examined, it was found that the self-efficacy of physical education and sports teacher candidates in educational game playing was high, but their self-efficacy in practice was lower than
\end{abstract}

\footnotetext{
* Corresponding author:

Tugay Çintesun, Department of Physical Education and Sports Teaching, Institute Social Sciences, Ardahan University, Ardahan, Turkey. Email: cintesuntugay36@gmail.com
} 
the other dimensions of the scale. In another sub-problem of the study, it was found that there was no statistically significant difference between teacher candidates 'educational game playing and their gender, but female teachers' self-efficacy mean scores were higher than male teacher candidates. Finally, when the relationship between pre-service teachers' self-efficacy for playing educational games and the classroom variable was examined, it was found that there was no statistically significant difference between the game-playing self-efficacy and the class variable.

Keywords: Educational game, self-efficacy, physical education and sports.

Received: 29 January 2021 * Accepted: 02 February 2021 * DOI: https://doi.org/10.29329/jcre.2020.287.3

\section{GíRiş}

Ebeveynler oyunu, çocukların eğlenmelerini ve güzel vakit geçirmelerini sağlayıcı herhangi bir amaca yönelik olmayan etkinlik olarak görebilmektedir. Hâlbuki oyun, bireyin yaşamında önemlidir. Birey için bir görevi veya işi ifade eder. Oyun kendiliğinden oluşan içeriğinde mutluluğu barındıran etkinlikler bütünüdür (Başal, 2007). Bireylerin oynadığg oyunlar ebeveynlerin gözünde eğlence faaliyeti olarak algılansa da aslında oyun bireyin eğitiminde ve kişiliğinin oluşumda büyük bir faktördür. Oyun bireyin zekâsını geliştirerek zamanla olgunlaşmasını sağlayan bir araçtır (Özer, Gürkan ve Ramazanoğlu, 2006).Oyunun sadece eğitim aracı olarak algılanmadığı bireyler arasında da iletişimi sağladığı bilinmektedir. Ayrıca Oyun, öğrencilerin öğretmenleri ile iletişim kurmasında da etken bir rol oynar. Uzmanlar bireylerin öğretmenleriyle yaptığı etkinliklerin bireyin oyun yeteneğini artırdığını bunun yanında matematiksel beceriyi, öğretmen ile iletişimi ve birçok yeteneği geliştirdiğini söylemişlerdir (Trawick-Smith, Swaminathan ve Liu, 2016). Oyun, bireyin hayatının her alanında yerini alır ve bireylerin gelişimine yardım eder. Bireylerin özellikle bebeklik dönemlerinden itibaren hayatı anlamasına olanak sağlar (Oktay, 2004; Koçyiğit ve Baydilek, 2015). Birey, oyunlar aracıllı̆̆ıla kendi kültürü ile bütünleşip oyun dünyasını var eder. Bu bireyin ebeveynlerin dünyasına hazırlık aşamasıdır. Birey oyun arac1lığı ile öz güven, dikkat, çabuk düşünme ve karar alma vb. duyguları edinir ve bu duyguları geliştirir. Çocuk oyun aracılığı ile kendini fark edilmez bir öğrenme ortamında bulabilir. Buna gerekçe olarak çocuğu öğrenmeye yönelten ayrıca çocuktaki öğrenme hevesini bireye aşılayan motivasyon duygusunun oyun içerisinde bulunmasıdır. Motivasyon ne kadar yüksek olursa öğrenme de o kadar anlamlı ve kalıcı olur. Bireylerin hazırbulunuşluk düzeyleri göz önünde bulundurularak etkinlikler yapılması gerekir. Bireylerin eğitilmelerinde oyun yönteminin tercih edilmesi, bireyin öğrenme ortamını daha etkili hale dönüştürdüğü ifade edilmektedir (Kıldan, 2001; Savaş ve Gülüm, 2014). Oyunların iyi planlanmış ve hazırlanmış olması öğretimin oluşmasına kolaylık sağlar. Fakat bu bağlam da öğreticinin konusuna hâkimliği, oyunların amacına uygun olması ve oyun sürecinin doğru bir biçimde yürütülmesi önemlidir. Oyun aracıllı̆g ile öğretim düğer yöntem ve tekniklere nispeten daha etkilidir. Nitekim oyun yönetimi dikkati, hayal gücünü, yaratıcıllğı ve problem çözmeyi ele alır (Bilen, 
1999; Önen, Demir ve Şahin, 2012). Bu bağlamda oyun yönteminin planlanma, uygulama ve değerlendirme sıralamasının dikkatli bir şekilde yürütülmesi gerekir. Çocukların oyun planı yapılırken bireylerin ilgi ve ihtiyaçları, hazırbulunuşluk seviyeleri ve gelişim özellikleri ön planda tutulmalıdır. Planlamanın uzun süreli ve karmaşık yapıda olmasından kaçınılmalıdır. Planlamanın ilgi çekiciliği, sadeliği ve eğlenceli yönleri ele alınmalıdır (Hazar, 2005,11; Akandere, 2002:1; Demirci vd., 2013:1). Oyunların ve etkinliklerin planlanmasının önemli olması kadar da uygulanması da önem arz etmektedir. Amaca yönelik olarak planlanan bir oyunun uygun olmayan yöntem ve ortamda kullanılması birey için eğitselliğini ve eğlendiriciliğini yitirmiş olur (Yiğit, Tuğluk ve Kök, 2007).Öğretmenlerin eğitim kurumlarında kendi oyun anlayışlarını oyunlara yüklediği ve oyunları bir ödül veya dinlenme aracı olarak kullandıkları için oyunun önemini kavrayamadıkları görülmüştür (Tuğrul vd., 2014; Çiftçi ve Önder, 2017; Özyürek ve Çavuş, 2016). Günümüz eğitim sisteminde halen öğretmen merkezli anlayışın sürdüğü ve bu anlayışın eğitim kurumlarındaki oyunları daiçine aldığı görülmektedir. Bu durumun bireylerin gelişimini ve oyun anlayışını olumsuz yönde etkilediği göstermektedir (Pyle ve Danniels, 2017; Miller ve Almon, 2009) Öğretmen, eğitim ortamlarında bireyleri olumlu yönde geliştirmek amacı ile yönlendirmeli ve bireylere problem çözme, işbirlikçi çalışma, sorumluluk duygusunu geliştirme ve öz düzenleme gibi kazanımlar elde etmelerini sağlamalıdır (Arslan, Çiftçi ve Önder, 2017). Eğitimde planlaması yapılan ve hali hazırda uygulanan programlarda önemli bir faktörde öğretmendir. Öğretmenin yer almadığı programların başarıya ulaşılabilirlik düzeyi düşüktür. Çünkü eğitim ortamında programın belirlenmesini ve uygulanmasını yapan baş aktör öğretmendir (Yazıcılar, 2016). Bundan ötürü oyunun öğretmen tarafindan nasıl işleneceği, nerede uygulanacağı öğretmenin oyunla alakalı tutumu ve bilgisi ile alakalıdır (Howard, 2010). Son dönemlerde eğitimde en büyük tartışma konularından biri de öğretmen yetiştirilmesi ve bu yetiştirilen öğretmenlerin yeterlilikleri konusudur. $\mathrm{Bu}$ yeterliliğin arttırılması için yapılacak çalışmalar da eğitim yöneticilerine düşmektedir. Öz yeterlilik bireyin bir işi yapabilme veya herhangi bir durum ile baş edebilmek için ortaya koyduğu çabanın hangi oranda gerçekleştiği olarak ifade edilebilir (Kahraman ve Çelik, 2019).

İlgili literatür incelendiğinde, öğretmeler için eğitsel oyunların önemli olduğu tespit edilmiştir. Buradan hareketle bu araştırmada beden eğitimi ve spor öğretmen adaylarının eğitsel oyun oynatma öz yeterlilikleri sosyo demografik değişkenler açısından incelenmesi amaçlanmıştır.

\section{Araştırmanın Alt Problemleri}

1. Beden eğitimi ve spor öğretmen adaylarının eğitsel oyun oynatma öz yeterliliği ne düzeydedir?

2. Beden eğitimi ve spor öğretmenliği bölümünde okuyan öğretmen adaylarının Eğitsel oyun oynatma öz yeterliliği cinsiyet değişkeni açısından farklılık göstermekte midir? 
3. Beden eğitimi ve spor öğretmenliği bölümünde okuyan öğretmen adaylarının Eğitsel oyun oynatma öz yeterliliği sınıf değişkeni açısından farklılık göstermekte midir?

\section{Araştırmanın Amacı}

Yapılan bu araştırmanın amacı beden eğitimi ve spor öğretmen adaylarının eğitsel oyun oynatma öz yeterliliklerinin sosyo demografik değişkenler açısından incelenmesidir.

\section{YÖNTEM}

\section{Araştırma Modeli}

$\mathrm{Bu}$ çalışmanın araştırma modeli tarama modelidir. Geçmişte ya da günümüzde sürekliliğini koruyan ve herhangi bir olayı olduğu haliyle betimleyen veya araştırmalara konu olan kişi, durum veya her hangi bir objeyi kendi imkânları doğrultusunda tanımlayan bir araştırma modelidir (Karasar, 2008).

\section{Evren ve Örneklem}

Bu çalışmanın örneklemini Kafkas Üniversitesi Beden Eğitimi ve Spor öğretmenliği bölümünde öğrenim gören 1,2, 3 ve 4.sınıf 111 öğretmen adayı oluşturmaktadır.

Tablo 1. Cinsiyet ve sınıf değişkeni

\begin{tabular}{lccc}
\hline Değişken & & Frekans (f) & Yüzde (\%) \\
\hline \multirow{2}{*}{ Sinıf } & 1.Sinıf & 19 & 17,1 \\
& 2. Sinıf & 25 & 22,5 \\
& 3. Sinıf & 28 & 25,2 \\
& 4. Sinıf & 39 & 35,1 \\
\hline Cinsiyet & Kadın & 65 & 58,5 \\
& Erkek & 46 & 41,4 \\
\hline Toplam & & 111 & 100 \\
\hline
\end{tabular}

Tablo 1'de sınıf ve cinsiyet değişkenine ait veriler incelendiğinde, öğrencilerin 19 (\% 17,1)'nun birinci sınıf, 25 (\% 22,5)'nin ikinci sınıf, 28 (\% 25,2)'nin üçüncü sınıf ve 39 (\% 35,1)'nin dördüncü sınıf olduğu tespit edilmiştir. Cinsiyet değişkenine göre ise öğrencilerin 65 (\%58,5)'nin kadın ve 46 (\% 41,4)'nün erkek olduğu belirlenmiştir.

\section{Veri Toplama Araci}

Bu çalışmada veri toplama aracı olarak Altınkök ve Yılmaz (2018) tarafından geliştirilen Eğitsel Oyun Oynatma Öz Yeterlilik Ölçeği kullanılmıştır. Bu ölçek, eğitsel oyun oynatan beden eğitimi bölümleri, sınıf öğretmenliği bölümleri veya okul öncesi öğretmenliği bölümlerinde okuyan veya mezun olmuş öğretmenlerin eğitsel oyun oynatma öz yeterliliklerini belirlemek amacı ile geliştirilmiştir. Ölçek 
toplam 11 maddeden ve üç alt boyuttan oluşmaktadır. Ölçek kesinlikle katılmıyorumdan (1) kesinlikle katılıyoruma (5) doğru 5'li likert şeklinde hazırlanmıştır. Ölçek alt boyutları; planlama(4 madde), uygulama (4 madde) ve değerlendirme ( 3 madde) şeklindedir. Ölçeğin geneline ait cronbach alpha güvenirlilik kat sayıs1 $0,88^{\prime}$ dir.

\section{Veri Analizi}

$\mathrm{Bu}$ çalışmada elde edilen verilerin analizinde SPSS 20.0 programı kullanılmıştır. Verilerin öncelikle betimsel analizleri yapılmıştır. Elde edilen ortalama ve standart sapmalar tablolaştırılmıştır. Cinsiyet değişkenine yönelik farklılığı belirlemek amacı ile MANOVA Testi yapılmıştır. Test öncesi verilerin MANOVA varsayımlarını karşılayıp karşılamadığına bakılmıştır. Sınıf değişkenine yönelik farklılığı belirlemek amacı ile de veriler MANOVA varsayımlarını karşılamadığı için ANOVA Testi yapılmıştır.

\section{Bulgular}

Bu çalışmada elde edilen bulgular alt problemler şeklinde düzenlenerek tablolaştırılmıştır.

Araştırmanın birinci alt problemi kapsamında "Beden eğitimi ve spor öğretmen adaylarının eğitsel oyun oynatma öz yeterliliği ne düzeydedir?" ifadesine yönelik elde edilen bulgular Tablo 2'de sunulmuştur.

Tablo 2. Öğretmen adaylarının eğitsel oyun oynatma öz yeterlik düzeyleri

\begin{tabular}{lccc}
\hline & $\mathbf{N}$ & $\overline{\mathbf{x}}$ & $\mathbf{S}$ \\
\hline Planlama & 111 & 4,43 &, 667 \\
Uygulama & 111 & 4,03 &, 801 \\
Değerlendirme & 111 & 4,48 &, 691 \\
\hline
\end{tabular}

Tablo 2'de öğretmen adaylarının eğitsel oyun oynatma öz yeterlik düzeyleri incelendiğinde, öz-yeterlik ölçeğinin tüm boyutlarında öğretmen adaylarının 4'ün üzerinde bir ortalamaya sahip oldukları görülmektedir. Özellikle planlama $(\overline{\mathrm{x}}=4,43)$ ve değerlendirme $(\overline{\mathrm{x}}=4,48)$ boyutunda öğretmen adaylarının çok yüksek öz yeterliğe sahip oldukları, uygulama boyutunda $(\bar{x}=4,03)$ ise yüksek özyeterliğe sahip oldukları belirlenmiştir.

Araştırmanın ikinci alt problemi kapsamında "Beden eğitimi ve spor öğretmenliği bölümünde okuyan öğretmen adaylarının Eğitsel oyun oynatma öz yeterliliği cinsiyet değişkeni açısından farklılık göstermekte midir?" ifadesine yönelik elde edilen bulgular Tablo 3’te sunulmuştur. 
Tablo 3. Çalışmaya Yönelik Betimsel İstatistik Sonuçları

\begin{tabular}{lcccc}
\hline & Cinsiyet & $\mathbf{N}$ & $\overline{\mathbf{x}}$ & $\mathbf{S}$ \\
\hline Planlama & Kadın & 65 & 4,48 &, 083 \\
& Erkek & 46 & 4,37 &, 099 \\
\hline Uygulama & Kadın & 65 & 4,10 &, 099 \\
& Erkek & 46 & 3,34 &, 118 \\
\hline Değerlendirme & Kadın & 65 & 4,67 &, 082 \\
& Erkek & 46 & 4,22 &, 097 \\
\hline
\end{tabular}

Tablo 3 incelendiğinde, planlama alt boyutunda kadın öğretmen adaylarının ortalamaları $(\overline{\mathrm{x}}=4.48)$ erkek öğretmen adaylarının ortalamaları ise $(\overline{\mathrm{x}}=4.37)$ 'dir. Uygulama alt boyutunda kadın öğretmen adaylarının ortalamaları $(\bar{x}=4.10)$, erkek öğretmen adaylarının ortalamaları $(\bar{x}=3.34)$ 'dür. Değerlendirme alt boyutunda kadın öğretmen adaylarının ortalamaları ( $\overline{\mathrm{x}}=4.67)$, erkek öğretmen adaylarının ortalamaları ise ( $\overline{\mathrm{x}}=4.22)$ 'dir. MANOVA testine ilişkin elde edilen istatistiki bulgular Tablo 4'te sunulmuştur.

Tablo 4. MANOVA Analizi Sonuçları

\begin{tabular}{lcccc}
\hline & Wilks' Lambda & $\mathbf{F}$ & $\mathbf{p}$ & $\boldsymbol{\eta}^{2}$ \\
\hline Planlama & & &, 414 &, 006 \\
Uygulama & \multirow{2}{*}{876} & 5,058 &, 303 &, 010 \\
Değerlendirme & & &, $001^{*}$ &, 102 \\
\hline$* 0<05$ & &
\end{tabular}
$* \mathrm{p}<.05$

Tablo 4 incelendiğinde, beden eğitimi ve spor öğretmenliği bölümünde öğrenim gören öğretmen adaylarının eğitsel oyun oynatma öz yeterliliği cinsiyet değişkeni açısından farklılık göstermekte midir?” alt problemini incelemek için MANOVA testi yapılmıştır. Analizde bağımlı değişkenler olarak planlama, uygulama ve değerlendirme alt boyutları alınmıştır.

Analiz öncesinde verilerin normalliğine ve doğrusallığına bakılmıştır. Çok değişkenleri uç değerler ve varyans, kovaryans matrisleri incelenmiş verilerin MANOVA testi yapmaya uygun olduğu belirlenmiştir. MANOVA analizi sonucu Tablo 4 incelendiğinde cinsiyet değişkenine göre planlama ve uygulama boyutunda herhangi bir fark olmadığı sadece değerlendirme alt boyutunda cinsiyet değişkenine göre bir farklılı̆̆ın olduğu görülmektedir.

Araştırmanın üçüncü alt problemi kapsamında "Beden eğitimi ve spor öğretmenliği bölümünde okuyan öğretmen adaylarının Eğitsel oyun oynatma öz yeterliliği sınıf değişkeni açısından farklılık göstermekte midir?" ifadesine yönelik elde edilen bulgular Tablo 5 'te sunulmuştur. 
Tablo 5. ANOVA testi sonuçları

\begin{tabular}{lcccccc}
\hline & $\begin{array}{c}\text { Varyans } \\
\text { kaynağı }\end{array}$ & $\begin{array}{c}\text { Kareler } \\
\text { toplamı }\end{array}$ & df & Kareler ort. & F & p \\
\hline Planlama & Gruplar aras1 & 1,307 & 3 &, 436 &, 976 &, 407 \\
& Gruplar içi & 47,751 & 107 &, 446 & & \\
\hline Uygulama & Gruplar arasi & 1,889 & 3 &, 630 &, 979 &, 406 \\
& Gruplar içi & 68,797 & 107 &, 643 & & \\
\hline Değerlendirme & Gruplar aras1 &, 281 & 3 &, 094 &, 191 &, 902 \\
& Gruplar içi & 52,338 & 107 &, 489 & & \\
\hline
\end{tabular}

Tablo 5'te öğretmen adaylarının öz-yeterliklerinin sınıf değişkenine göre istatistiki açıdan anlamlı fark bulunmadığı belirlenmiştir ( $\mathrm{p}$ >.05). Ölçeğin faktörleri ile sınıf değişkeni arasındaki istatistiki ilişki incelemek amacıyla yapılan ANOVA test sonuçları incelendiğinde, planlama alt boyutu $(\mathrm{F}=, 976$; $p>0.05)$, uygulama alt boyutu $(F=, 979 ; p>005)$ ve değerlendirme alt boyutunda $(F=, 191 ; p>0.05)$ olduğu belirlenmiştir.

\section{Tartışma ve Sonuç}

Beden eğitimi ve spor öğretmen adayları ile yapılan bu çalışmada öncelikle öğretmen adaylarının eğitsel oyun oynatma öz yeterlilik düzeylerine bakılmıştır. Elde edilen sonuçlar beden eğitimi ve spor öğretmen adaylarının eğitsel oyun oynatma öz yeterliliklerinin yüksek olduğu sonucu elde edilmiştir. İlgili literatür incelendiğinde, Akçınar (2018) beden eğitimi ve spor öğretmenleri ile yaptığı çalışmada öğretmen adaylarının eğitsel oyun oynatma beceri düzeylerinin çok yüksek düzeyde olduğunu, bu sonucun aksine Akcanca ve Sömen (2018) fen bilgisi ve sosyal bilgiler öğretmen adayları ile yaptıkları çalışmada ise öğretmen adaylarının eğitsel oyun oynatma konusunda zorlandıklarını ve bazı sorunlar yaşadıklarını belirlemişlerdir. Dalaman (2015) yaptığı çalışmada öğretmen adaylarının beden eğitimi ve oyun öğretimi dersine yönelik tutumlarının düzenli spor yapanlarda daha olumlu düzeyde olduğunu yönünde sonuçlar elde etmiş̧tirler. Çalışmanın diğer bir alt probleminde beden eğitimi ve spor öğretmen adaylarının eğitsel oyun oynatma öz yeterlilik düzeylerinin cinsiyet değişkenine göre farklılık gösterip göstermediği incelenmiştir. Elde edilen sonuçlar kadın öğretmen adaylarının eğitsel oyun oynatma sonrası değerlendirme noktasında öz yeterliliklerinin erkek öğretmen adaylarına göre daha iyi olduğunu göstermektedir. Akçınar (2018) beden eğitimi ve spor öğretmen adayları ile yaptığı çalışmada öğretmen adaylarının eğitsel oyun oynatma becerilerinin cinsiyet değişkenine istatistiki açıdan fark bulunmadığı, Yılmaz, Kırımoğlu ve Yamanyurt (2019) çalışmalarında beden eğitimi ve spor öğretmenleri ile sınıf öğretmenlerinin eğitsel oyun oynatma öz yeterlilik düzeylerini incelemiş ve cinsiyet değişkeni ile oyun oynatma öz yeterliliği arasında istatistikî bir ilişki bulunmadığı yönünde sonuçlar elde etmiştirler. Bu sonuçlar göstermektedir ki beden eğitimi ve spor öğretmen adaylarının eğitsel oyun oynatma öz yeterliklerinin cinsiyet değişkenine göre farklılaşmadığını belirleyen çalışmalarda bulunmaktadır. $\mathrm{Bu}$ doğrultuda bu konuda daha fazla çalışma yapılması gerektiği düşünülmektedir. Bu çalışmanın diğer bir 
sonucu olarak beden eğitimi ve spor öğretmen adaylarının eğitsel oyun oynatma öz yeterlilikleri ile sınıf değişkeni arasında istatistiki açıdan anlamlı bir fark bulunmadığı sonucu elde edilmiştir. Bu durum öğretmen adaylarının sınıfları değişse bile öz yeterliliklerinin değişmediğini göstermektedir.

\section{KAYNAKÇA}

Akçınar, S. (2018). Beden Eğitimi Öğretmenlerinin Eğitsel Oyun Oynatma Becerilerinin İncelenmesi, Beden Eğitimi ve Spor Anabilim Dalı Doktora Programı, İnönü Üniversitesi, Yayımlanmamış Doktora Tezi. Malatya

Arslan Çiftçi, H. ve Önder, A. (2017). Erken Çocuklukta Oyun ve Oyun Yoluyla Öğrenme. Nobel Akademik Yayıncılık: Ankara

Başal, H. A. (2007). Geçmiş yıllarda Türkiye'de çocuklar tarafindan oynanan çocuk oyunları. Uludă̆ Üniversitesi Eğitim Fakültesi, 20(2), 243-266.

Bilen, M. (1999). Plandan Uygulamaya Öğretim. Ankara: Anı Yayıncılık.

Dalaman, O. ve Korkmaz, İ. (2010). İlköğretim Birinci Kademede Beden Eğitimi Dersine Giren Öğretmenlerin Beden Eğitimi Öğretim Programı Kazanımlarına İlişkin Görüşleri. Niğde Üniversitesi Beden Eğitimi ve Spor Bilimleri Dergisi, 4, (3), 172.185.

Hazar, M. (2005). Beden Eğitimi ve Sporda Oyunla Eğitim. Ankara: Tutibay Yayıncılık.

Howard, J. (2010). Early years practitioners' perceptions of play: An exploration of theoretical understanding, planning and involvement, confidence and barriers to practice. Educational and Child Psychology, 27(4), 91-102.

Kahraman, Ü. ve Çelik, K. (2019). Eğitim Fakültesi Öğrencilerinin Öz Yeterlilik İnançları İle Mesleki Kaygıları Arasındaki İlişki. Pamukkale Üniversitesi Eğitim Fakültesi Dergisi, 45, 353-375.

Karasar, N. (2008). Bilimsel Araştırma yöntemi. Ankara: Nobel Yayın dağıtımı.

Koçyiğit, S. ve Baydilek., N.B. (2015). Okul Öncesi Dönem Çocuklarının Oyun Algılarının İncelenmesi. YYÜ Ĕ̈itim Fakültesi Dergisi, 12(1), 1-28.

Akcanca, N. ve Sömen., T. (2018). Öğretmen Adaylarının Eğitsel Oyun Tasarlama ve Uygulama Durumları. Turkish Studies, 13(27), 49-71.

Oktay, A. (2004). Yaşamın Sihirli Yılları: Okul Öncesi Dönem (5. Baskı). İstanbul: Epsilon Yayıncılık. Kıldan, A. O. (2001). Oyunun Çocukların Gelişim Özelliklerine Etkisi. Yayınlanmamış Yüksek Lisans Tezi, Selçuk Üniversitesi, Konya

Özer, A., Gürkan, A. C., ve Ramazanoğlu, O. (2006). Oyunun Çocuk Gelişimi Üzerine Etkileri. Fırat Üniversitesi Doğu Araştırmaları Dergisi, 4(3), 54-57.

Pyle, A. ve Danniels, E. (2017). A Continuum of Play-Based Learning: The Role of the Teacher in PlayBased Pedagogy and the Fear of Hijacking Play. Journal Early Education and Development, 28(3), 274-289.

Trawick-Smith, J., Swaminathan, S. ve Liu, X. (2016). The relationship of teacher-child play interactions to mathematics learning in preschool. Early Child Development \& Care, 186 (5), 716-733. 
Tuğrul, B., Aslan, Ö.M., Ertürk, G, ve Altınkaynak, Ş. Ö. (2014). Anaokuluna Devam Eden Altı Yaşındaki Çocuklar İle Okul Öncesi Öğretmenlerinin Oyun Hakkındaki Görüşlerinin İncelenmesi. İnönü Üniversitesi Ĕ̆itim Fakültesi Dergisi, 15(1), 97-116.

Yazıcılar, Ü. (2016). Öğretmenlerin Matematik Dersi Öğretim Programını Uyarlama Sürecinin İncelenmesi. (Yayınlanmamış Yüksek Lisans Tezi), Ege Üniversitesi. Sosyal Bilimler Enstitüsü, İzmir.

Yılmaz., A, Kırımoğlu., H ve Yamanyurt., M. (2019). Beden Eğitimi ve Sınıf Öğretmenlerinin Eğitsel Oyun Oynatma Öz Yeterliliklerinin Çeşitli Değiş̧kenler Açısından İncelenmesi (Van İl Örneği). Turkish Studies, 14(7), 4131 - 4144. 